\title{
Early clinical exposure to enhance the learning of biochemistry in first year M.B.B.S students
}

\author{
Amandeep Kaur ${ }^{1, *}$, Sahiba Kukreja², Tejinder Singh³, Mandeep Kaur ${ }^{4}$ \\ ${ }^{\mathbf{1}}$ Associate Professor, ${ }^{2}$ Professor and Head, Dept. of Biochemistry, Sri Guru Ram Das Institute of Medical Sciences and Research, \\ Amritsar, Punjab, ${ }^{3}$ Lieutenant Colonel, Army Medical Corps., ${ }^{4}$ Assistant Professor, Dept. of Biochemistry, Sri Guru Ram Das \\ Institute of Medical Sciences and Research, Amritsar, Punjab, India
}

*Corresponding Author:

Email: amandeepbest@gmail.com

Received: $26^{\text {th }}$ March, 2018

Accepted: $29^{\text {th }}$ March, 2018

\begin{abstract}
Introduction: Biochemistry is taught using teacher centred method i.e lectures where students are passive learners. In first year of M.B.B.S, students don't feel the importance of biochemistry in clinical practice. As a result, they are not motivated to study this subject. To overcome this, student centred strategies like early clinical exposure via case based learning (CBL) is needed to relate basic sciences subject with clinical scenario and apply concepts of theory to clinical conditions.

Aim and Objectives: 1. To sensitize faculty and students about CBL; 2. To introduce CBL as teaching learning tool in department of biochemistry; 3. To assess perception of faculty and students regarding CBL; 4. To make the students aware of relevance of biochemistry in clinical settings.

Materials and Methods: In this study, a new teaching learning intervention was devised in Biochemistry department of SGRDIMSAR, Amritsar which comprised of ECE program consisting of CBL. Total 133 students of first year M.B.B.S were involved in this study after their consent. All the participants $(n=133)$ were divided into 2 groups; Group A (n= 67) and Group B $(n=66)$. Further each group was divided into 5 sub groups i.e Group A into sub groups A1 $(n=14), A 2(n=14), A 3(n=13)$, A4 $(n=13)$, A5 $(n=13)$ and Group B into B1 $(n=14), B 2(n=13), B 3(n=13), B 4(n=13), B 5(n=13)$. There were 5 facilitators, one for each sub group. All were taught by case based learning method. The outcomes and effectiveness of this intervention was assessed by a MCQs pre-test/ post-test model of cognitive knowledge acquisition used to identify knowledge gain and effectiveness of the educational intervention. Students and faculty attitude towards early clinical exposure via CBL was assessed by 5 point Likertscale questionnaire survey.

Results: After CBL method, students had improved scores in evaluation test and the difference was statistically highly significant. Majority of students and faculty opined that CBL was useful, arouse interest, helpful in better understanding of clinical biochemistry topic, and link clinical knowledge with basic biochemistry.

Conclusion: ECE is a useful method for a basic science like biochemistry if it is taken up with the traditional teaching method. The present study concluded that CBL improves academic performance of students and motivates the students for self- directed learning by increasing their interest in subject and promotes meaningful learning, student reasoning and communication skills. Majority of faculty and students were satisfied with the introduction of this teaching learning tool. 100\% faculty and $98 \%$ students felt that biochemistry was relevant in clinical setting. So, CBL should be used as a regular method at appropriate places in curriculum of biochemistry.
\end{abstract}

Keywords: Early clinical exposure, CBL, Biochemistry, M.B.B.S students.

\section{Introduction}

Biochemistry is one of the foundation sciences in the medical curriculum, which has immense importance in understanding the future clinical sciences, but it is generally considered to be a subject of just countless biochemical structures, pathways and reactions. In the traditional system of medical education, it was mainly taught by means of didactic lectures, tutorials and practical classes, along with anatomy and physiology in the first year of the medical course of four and a half years duration. Hence, it was teacher centered, with minimal active participation from the students and hence, the students lacked critical thinking. But these days, the education system is changing to a student centered teaching-learning process with the use of various innovative teaching methods. This makes the students actively involved in the process of learning and it thus prepares them for a lifelong self directed learning process. ${ }^{1}$

The subject of biochemistry is a key subject which forms the base of laboratory medicine and includes diagnostic methodology. Clinical biochemistry topics link the basic knowledge with clinical content. Hence, these topics are extremely important in learning process and for practice of medicine in future. ${ }^{2}$ Early clinical exposure ensures well integrated knowledge of the basic sciences, clinical sciences and social functions especially doctor-patient interaction. Education system across the world now emphasise early clinical exposure towards horizontal and vertical integration and contextual learning in the local settings. Keeping in mind the implications of ECE, Medical council of India, New Delhi, has recommended ECE in new proposed syllabus from $2015 .^{3}$ 
ECE through Case Based Learning (CBL) is one such approach which can make learning more effective and interesting. CBL is an established pedagogical method that uses case studies as active learning tools. CBL uses a clinical case or problem or inquiry to stimulate and underpin the acquisition of knowledge, skills and attitudes. CBL promote authentic learning and allows students to develop a collaborative, team based approach to their education. CBL uses a guided enquiry method and provides structure during small group sessions. The main role of facilitator is to assist the students through the facts and to engage in analysis and the development of possible solutions and strategies. ${ }^{4}$ Case method involves learning by doing and developing analytical and decision making skills which is closely related to learning objectives in clinical biochemistry. $^{5}$

\section{Aim and Objectives}

1. To sensitize faculty and students about CBL.

2. To introduce CBL as teaching learning tool in department of biochemistry.

3. To assess perception of faculty and students regarding CBL.

4. To make the students aware of relevance of biochemistry in Clinical settings.

\section{Materials and Methods}

133 voluntary participants were first year M.B.B.S. students for academic year 2015-2016, who consented to undergo study at the institute. The present interventional study was conducted after obtaining institutional ethical committee approval. Sensitization of faculty and students about CBL with progressive disclosure was done as per schedule. Topic of CBL module was given to students 1 week in advance. CBL with progressive disclosure was conducted during practical classes on two consecutive days. The students of first year M.B.B.S. not willing for participation were excluded from the present study. All the participants $(n=133)$ were divided into 2 groups; Group A $(n=67)$ and Group B $(n=66)$. Participants were evaluated with pre-test in the form of MCQs with one best possible answer related to the topic selected. This score evaluates all the participants and is the pre test score for all the participants. Further each group was divided into 5 sub groups i.e Group A into sub groups A1 $(n=14)$, A2 $(n=14), A 3(n=13), A 4(n=13), A 5(n=13)$ and Group B into B1 $(n=14), B 2(n=13), B 3(n=13), B 4$ $(n=13), B 5(n=13)$. There were 5 facilitators, one for each sub group. The participants were presented with a case based on the same clinical biochemistry topic. Same case was given to both groups. The case was a clearly defined clinical problem consisting of symptoms and laboratory data. Then participants in small groups were given enough time to identify, discuss and resolve the problem with progressive disclosure. Subsequently they were provided with specific learning objectives for the case and then facilitators motivate and guided them to discuss the case. The facilitators ensured that all participants of each sub group were involved in discussion. Participants were encouraged to ask the questions. Then these participants were evaluated with post-test in the form of same set of MCQs. To evaluate the participants and faculty perception towards CBL, a qualitative feedback questionnaire with Likert scale consisting open ended and close ended questions on acceptability and usefulness of this method was taken from both the participants and faculty. The response obtained was in terms of strongly agree, agree, neutral, disagree and strongly disagree. This questionnaire was validated by the members of MEU of institute.

\section{Statistical Analysis}

The data was analyzed by SPSS software, version 11. The numerical data of pre and post test is expressed in terms of mean $\pm S D$. Student ' $t$ ' test was used to compare the continuous variables between the groups. For pre and post test comparison of Group A and Group $\mathrm{B}$, paired ' $\mathrm{t}$ ' test was used. The $\mathrm{p}$ vaue of $<0.05$ was considered to be statistically significant.

\section{Results}

Table 1 shows comparison of pre and post evaluation test for CBL. This comparison shows that post CBL score is improved and statistically highly significant $(p<0.001)$. Regarding perception of the students and faculty, no one thought that CBL was not helpful. $97.74 \%$ students $(63.91 \%$ strongly agree while $33.83 \%$ agree) stated that CBL was very helpful for understanding case study. $96.99 \%$ students opined that CBL motivated them for learning and there is facilitation of interaction between staff and students through CBL discussion sessions $(58.65 \%$ SA while $38.34 \%$ A). $85.71 \%$ students felt that clinical case arouse their interest in clinical biochemistry topics $(64.66 \%$ SA while $21.05 \%$ A). $90 \%$ students opined that $\mathrm{CBL}$ is better than lecture method for clinical biochemistry topic $(57.89 \% \quad \mathrm{SA}$ and $32.33 \% \mathrm{~A})$. 98.49\% students opined with that CBL helped to link clinical knowledge with basic biochemistry $(60.90 \%$ SA and $37.59 \%$ A). $90.97 \%$ students felt that it is helpful in interpretation of laboratory results and in diagnosis $(52.63 \% \mathrm{SA}$ and $38.34 \% \mathrm{~A}) .99 \%$ students stated that role of facilitator was important in session (71.43\% SA while $27.81 \%$ A). $94.73 \%$ students stated that group discussion was helpful during session (49.62\% SA while $45.11 \%$ A). $94.73 \%$ students opined that CBL promote meaningful learning, student reasoning and communication skills $(56.39 \%$ SA while $38.34 \%$ A). $97.74 \%$ students opined that more CBL sessions to be added in future $(56.39 \%$ SA while $41.35 \%$ A. (Fig. 1)

The following are some of the responses to the open ended question in the student feedback questionnaire: 
Shortcomings in this methodology: Most of the students comment that shortcoming at their part only because they were not come prepared for it.

In group discussions few of them were not showing interest and active participation.

Suggestions to improve it: CBL should be held as soon as the topic is covered in class.

More such sessions to be added in future.

Small group discussions are very helpful.

Regarding perception of faculty, $100 \%$ faculty opined that students participate actively in CBL sessions. $80 \%$ of faculty marked strongly agree that it is a good teaching learning tool and case discussion sessions facilitate interaction between students and faculty and it helped to link clinical knowledge with basic biochemistry. Majority of faculty $(60 \%)$ marked strongly agree that CBL helped students in critical thinking, in depth understanding of the topic and the role of facilitator is also utmost important. Most of the faculty felt that CBL promote meaningful learning, student reasoning and communication skills. (Fig. 2)

The following are some of the responses to the open ended question in the faculty feedback questionnaire:

\section{Shortcomings in this Methodology}

1. Teaching in basic subjects should not totally base on CBL method. So, for the complete knowledge of the subject CBL should be used in collaboration with other teaching learning methods.

2. Students were not come prepared for it so had to put in an extra effort to get students involved

\section{Suggestions to improve it}

1. CBL should be followed by theory lecture.

2. Number of such sessions should be increased and one day should be allotted for CBL at the end of related topic in theory classes.

Table 1: Comparison of pre and post evaluation test for CBL

\begin{tabular}{|l|c|c|c|c|c|}
\hline MCQs evaluation & N & Mean \pm SD & Difference & 't' value & P value \\
\hline Pre-Test & 133 & $8.308 \pm 2.027$ & $1.737 \pm 1.973$ & 10.153 & $<0.001^{* *}$ \\
\cline { 1 - 3 } Post-Test & 133 & $10.045 \pm 1.482$ & & & \\
\hline
\end{tabular}

$* * \mathrm{p}<0.001 ;$ Highly Significant

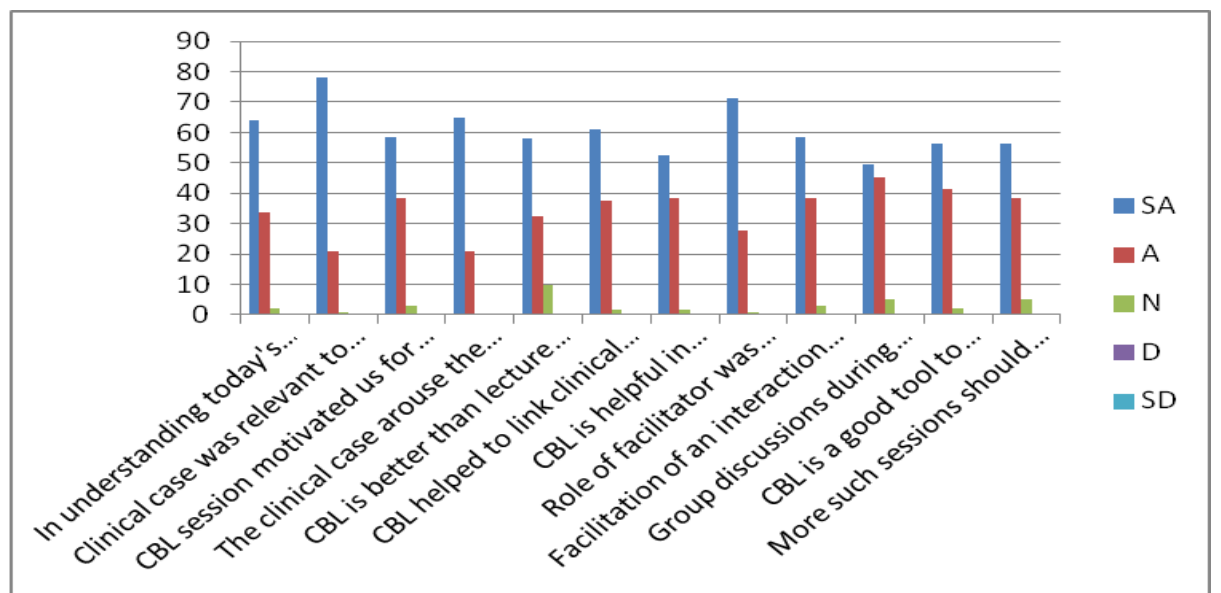

Fig. 1: Students feedback: Results of perception based questionnaire

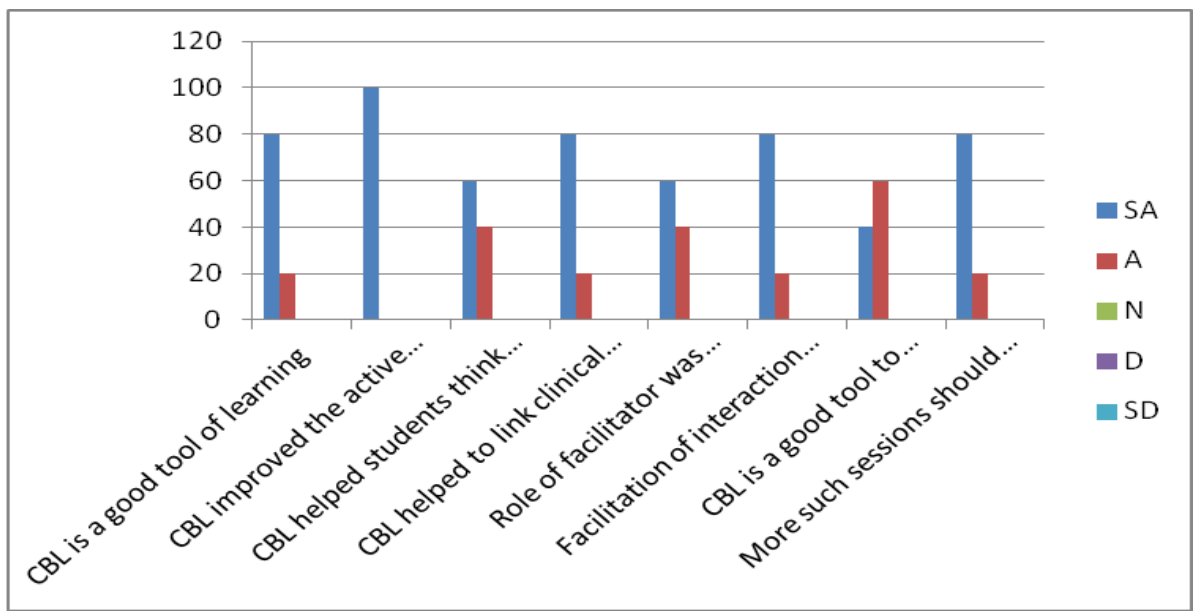

Fig. 2: Faculty feedback: Results of perception based questionnaire 


\section{Discussion}

Medical Council of India desires an increase in integration in order to provide students with a holistic rather than fragmented learning perspective. At the beginning of the medical profession, it is seen that students are not exposed to interrelatedness of scientific, social, professional and interpersonal elements of the field of medical education. Thus, gradually it became clear that the clinical context, which the preclinical phase would ultimately serve, should be introduced earlier. ${ }^{6}$

In the present study, early clinical exposure through CBL was used as a teaching learning tool than traditional method. Based on results of evaluation test, this study shows improved academic performance by the students. In our study, the increase in score in post test after CBL is extremely significant. This makes CBL educationally more valuable. These results are supported by studies by Agida U et al, Surpaneni K M et al, Nair P $\mathrm{S}$ et al and Joshi et al which show improved test scores post CBL session. . $^{7,8,1,2}$

Therefore the purpose for early clinical exposure in the 1st year is to learn basic clinical skills, enhance their motivation and prepare them towards the purpose for which they entered the profession, enable students to correlate what they are learning in basic sciences by learning basics clinical skills and observing relevant disease abnormalities, encourage students to learn the professional behaviour of a doctor by observing and being facilitated by a teacher and provide the context for application of their learning in practice. ${ }^{[9]} \mathrm{CBL}$ session in biochemistry is a guided enquiry method in which students face case scenario. The students have to think, define, struggle with problem and try to resolve it. This process enhances students' ability to synthesize, evaluate and apply information and concepts. ${ }^{2}$

Other benefits of CBL are: intrinsic and extrinsic motivation is developed, allowing individualised learning; encourages self evaluation and critical reflection; allows scientific inquiry and the development of support for their conclusions; integration of knowledge and practice and development of learning skills. CBL also allows students to develop a collaborative, team based approach to their education. It helped them in developing logical thinking, clinical reasoning and diagnostic interpretation. The drawback of this method at first year level may be that teaching style may not accurately match the learner stage. The learner at this level is dependent and interested and role of teacher in CBL is more of a facilitator. Also, first year students are not thoroughly aware of pathology and medicine aspects of a clinical case. Hence all the aspects of a clinical case cannot be discussed at this level. Hence, formulating cases appropriately and stating specific learning objectives is challenging and crucial at first year stage. To summarize, we introduced a newer method of teaching with positive and encouraging results. The results of the current study and the feedback of the students and faculty encouraged us in using CBL as a method of teaching, as it had a lot of positive impact on the students.

\section{Conclusion}

The present study concluded that CBL improves academic performance of students and motivates the students for self- directed learning by increasing their interest in subject and promotes meaningful learning, student reasoning and communication skills. Majority of faculty and students were satisfied with the introduction of this teaching learning tool. 100\% faculty and $98 \%$ students felt that biochemistry was relevant in clinical setting.

Limitation of the Study: The limitation of this study is that CBL session was conducted for only one topic as extensive preplanning and faculty training is required for such exercise. We suggest larger study with appropriate cases in entire curriculum of biochemistry and studying its effect.

\section{Outcome}

What this Study adds: CBL promotes meaningful learning, student reasoning and communication skills. This method definitely helps students to understand the relevance of biochemistry in clinical settings, motivated them and arouse interest in subject. The purpose for early clinical exposure in the 1st year is that students learn basic clinical skills and prepare them towards the purpose for which they entered the profession, and also enable students to correlate what they are learning in basic sciences by learning basics clinical skills.

Implications: ECE helps students to link basic knowledge with clinical content. ECE through CBL is one such approach which can make learning more effective and interesting. It also promotes students reasoning and communication skills. So, CBL should be used as a regular method at appropriate places in curriculum of biochemistry.

\section{References}

1. Nair P S, Shah T, Seth S, Pandit N, Shah G V. Case based learning: A method for better understanding of biochemistry in medical students. JCDR. 2013;7(8):15768.

2. Joshi K B, Nilawar A N and Thorat A P. Effect of case based learning in understanding clinical biochemistry. International journal of biomedical and advanced research. 2014;5(10):516-8.

3. MCI Booklet; Vision 2015, downloaded from www.mci.org.

4. Setia S, Bobby Z, Ananthanarayanan P, Radhika M, Kavitha M, Prashanth T Case Based Learning Versus Problem Based Learning: A Direct Comparison from First Year Medical Students Perspective. Webmed Central medical education. 2011;2(6):WMC001976.

5. Harreid C F. Case studies in science-A novel method of science education. JCST. 1994;23(4):221-9. 
6. Rawekar A, Jagzape A, Srivastava T, Gotarkar S. Skill learning through early clinical exposure: An experience of Indian Medical School. Clin Diagn Res. 2016;10(1):JC01-04.

7. Adiga U, Adiga S. Case based learning in biochemistry. International Journal of Pharma and Bio Sciences. 2011;2(2):B332-6.

8. Surpaneni K M. The Effect of Integrated Teaching with Case Based Learning (CBL) In the Biochemistry of Undergraduate Medical Curriculum. JCDR. 2010;4(5):3058-63.
9. Tayade M C, Bhimani N, Kulkarni N B. The impact of early clinical exposure on first M.B.B.S. students. International Journal of Healthcare and Biomedical Research. 2014;2(4):176-81.

How to cite this article: Kaur A, Kukreja S, Singh T, Kaur M. Early clinical exposure to enhance the learning of biochemistry in first year M.B.B.S students. Int J Clin Biochem Res. 2018;5(3):401-405. 